\title{
ESTUDIOS
}

\section{El nervio humanista de la universidad}

\section{Josep Miralles Massanés S.I.'}

Resumen: Reflexión sobre las características de una universidad que quiera ser realmente "humanista" en el contexto social actual. La universidad debe estar al servicio de la sociedad entera, no sólo de los grupos dominantes, y para ello debe hacer una opción por los pobres. Por otra parte, en sociedades culturalmente plurales la universidad debe promover el diálogo intercultural e interreligioso y favorecer la indagación de caminos de crecimiento espiritual más allá de las diferentes tradiciones religiosas. Para ello la universidad ha de educar "la persona entera" y asumir una antropología compleja que dé cuenta de la multidimensionalidad del ser humano. Aunque pueda parecer paradójico, este tipo de universidad generaría una capacidad de innovación y creatividad que la haría más capaz de enfrentar los desafíos actuales de nuestras sociedades.

Palabras clave: Diálogo intercultural, Diálogo interreligioso, Espiritualidad, Ética de máximos, Ética de mínimos, Humanismo, Opción por los pobres, Universidad.

\section{The nerve humanist of the University}

Abstract : reflection on the characteristics of a University that wants to really be " humanist $"$ in the current social context. The university must serve the whole society and not only the dominant groups and it must make an option for the poor. Moreover, in a plural-culturally societies, universities must promote intercultural dialogue and inter-religious dialogue and promote ways of spiritual inquiry beyond

\section{L'élan humaniste de l'université}

Résumé: Réflexion sur les caractéristiques d'une université qui veut être vraiment «humaniste» dans l'actuel contexte sociale. L'université doit servir la société tout entière et non pas seulement les groupes dominants et il doit faire une option pour les pauvres. En outre, dans des sociétés culturellement diverses, les universités doivent promouvoir le dialogue interculturel et interreligieux

'Profesor del Departamento de Ciencias Sociales, ESADE (Universidad Ramon Llull), Barcelona. josep.miralles1@esade.edu 
the different religious traditions growth. So the University has of educating "the whole person" and assume a complex anthropology which realises the multi-dimensionality of the human being of the human being. Although it may seem paradoxical, this kind of university would generate a capacity for innovation and creativity that would make it better able to meet the current challenges of our societies.

Keywords: intercultural dialogue, interreligious dialogue, spirituality, ethics of maximums, ethics of minimums, humanism, option for the poor, University.

Recibido: 30 de septiembre de 2015. ainsi que promouvoir des moyens d'enquête spirituelle au-delà de la croissance des différentes traditions religieuses. Pour cela, l'université doit éduquer « toute la personne » et assumer une anthropologie complexe qui prend en compte la multidimensionnalité de l'être humain. Bien que cela puisse sembler paradoxal, ce genre d'université serait la seule à générer une capacité d'innovation et de créativité qui la rendent plus en mesure de faire face aux actuels défis de nôtres sociétés.

Mots clé: dialogue interculturel, dialogue interreligieux, spiritualité, l'éthique des maximums, l'éthique des minimums, humanisme, l'option pour les pauvres, université. 


\section{Introducción}

Quisiera empezar mi reflexión sobre la relación universidad-humanismo con dos consideraciones previas ${ }^{2}$.

En primer lugar, quisiera expresar lo que podríamos llamar la "música de fondo" de mi intervención: la admiración por la tarea universitaria y por los que la llevan a cabo en cuanto tarea humana.

Explico lo que quiero decir con una anécdota: Cuando tratábamos de implementar el "Plan Bolonia" en ESADE, nos planteamos cuales deberían ser las competencias que definieran al buen profesional $y$, previamente, al "buen universitario". Una compañera me planteó la pregunta: " ¿Cómo quisieras que fuera una persona que ha pasado por nuestra universidad?". Pillado de sorpresa, contesté lo que llevaba dentro: me gustaría que fuera alguien con una gran curiosidad por saber, que disfrutara aprendiendo, que no se saciara nunca, que fuera capaz de admirarse y que tuviera sentido crítico, es decir, que no se conformara con la explicaciones de siempre ni aceptara como legítimas situaciones intolerables de nuestro mundo por el sólo hecho de que fuera difícil cambiarlas. Ya un poco más calmado, añadí que tuviera visión social: que aspirara a una sociedad más justa y libre....

He citado la anécdota porque contrasta con las razones que en muchos casos han impulsado la creación de universidades. En una reciente visita a Salamanca, la guía nos explicó que la universidad tenía su origen en un "Estudio general" creado por los reyes de León y Castilla para formar los funcionarios necesarios en unos reinos progresivamente más grandes y complejos. Más modernamente, establecimientos universitarios como ICADE, ESADE y ETEA surgieron en un momento en que el desarrollo económico de España empezaba a basarse en un tipo de empresa que necesitaba directivos formados de manera específica para ello. Es decir: las universidades han sido creadas en función de necesidades pragmáticas de las sociedades y de grupos de interés (normalmente con dinero e influencia) dentro de ellas. Sin embargo, afortunadamente, las universidades no producen sólo profesionales competentes para enfrentarse a problemas pragmáticos y para defender los intereses de quienes les pagan, sino también el tipo de persona que yo intentaba describir. $Y$ esto es una suerte, porque estas personas son las que permiten a la universidad realizar sus aportaciones más importantes a la sociedad.

${ }^{2}$ Quiero agradecer a José Sols, organizador del II Simposio UNIJES de Pensamiento Social Cristiano, su amable invitación a reflexionar sobre el impacto del humanismo en la universidad. 
De hecho, la universidad ha ido más allá de su funcionalidad meramente utilitaria, abriéndose una y otra vez a esta extraña cualidad del ser humano que es capaz de admiración, de curiosidad desinteresada, de sentido crítico, en definitiva de "trascender": no en el sentido directamente religioso que ha tomado habitualmente la palabra, sino en el sentido más general de buscar siempre un "más allá" que se expresa en nuevos conocimientos, en innovación y creatividad y en sentido crítico $^{3}$. Esta capacidad humana se expresa también como capacidad de amor y solidaridad, es decir, como salida de los propios intereses egocéntricos. Y una y otra cosa son las que permiten la actividad transformadora del ser humano sobre su entorno, una transformación que es humana y humanizadora. Esta es la "cualidad" más característica del ser humano y el humanismo (el cultivo de esta cualidad específicamente humana) ha estado presente en el origen y en el desarrollo de la universidad, al menos como una posibilidad más o menos desarrollada pero siempre esencial, de modo que donde desaparece, la misma universidad fracasa. ${ }^{4}$

Este pasar de lo pragmático y utilitario a lo gratuito y "des-interesado" me ha maravillado siempre y quiero reivindicarlo al ofrecer mis reflexiones, probablemente demasiado "idealistas" sobre el humanismo en la universidad.

En segundo lugar, y de modo coherente con lo que acabo de decir, quiero ponderar el título de la ponencia que me fue ofrecida por la organización de este Simposio: "El nervio humanista de la universidad".

La metáfora del "nervio" es muy sugerente. En el organismo humano, los nervios conectan el cerebro con las distintas partes del cuerpo y también éstas entre sí. El resultado es la posibilidad de movimientos ordenados y coordinados al servicio de la totalidad del ser humano. Gracias a los nervios no existe una yuxtaposición de órganos sino un organismo vivo y único. Podemos pensar que el humanismo impulsa el trabajo docente e investigador interdisciplinar de la universidad para

"El poeta Joan Maragall expresó maravillosamente esta cualidad humana en su poema "Excelsior": Vigila, esperit, vigila, / no perdis mai el teu nord, / no et deixis dur a la tranquilla / aigua mansa de cap port. / Gira, gira els ulls enlaire, / no miris les platges roïns, / dóna el front en el gran aire, / sempre, sempre mar endins (Vigila, espíritu, vigila, no pierdas nunca el norte, no te dejes llevar a la tranquila agua mansa de algún puerto. Eleva los ojos, no mires las playas ruines, levanta la frente al gran aire, siempre, siempre, mar adentro; traducción literal de las dos primeras estrofas del poema por el autor del artículo).

${ }^{4}$ M. CORBÍ (2007) Capítulo I. Mariano Corbí ha trabajado mucho este tema y toda su extensa bibliografia se basa en esta idea de la capacidad del ser humano de crear cultura para sobrevivir y a la vez de acceder a una captación "des-interesada" de la realidad. 
que integre y transforme la necesaria especialización de conocimientos prácticos en saberes orientados a la Sabiduría, una Sabiduría capaz de orientar la vida entera con sentido.

Es esta una tarea difícil: ¿̇de dónde puede sacar la universidad las fuerzas para realizarla? La metáfora del nervio responde a esta pregunta porque los nervios tensan los músculos, transmiten y concentran energía. Podríamos pensar que el humanismo, entendido como el amor a lo humano, a todo lo humano, debería ser el "nervio" que aportara energía a la tarea universitaria de crear conocimiento, trasmitirlo e integrarlo en una Sabiduría superior.

Finalmente, los nervios permiten expresar las emociones. El humanismo debería propiciar una universidad "em-pática", "com-pasiva", entusiasta, capaz de sintonizar ${ }^{5}$ con los sentimientos de las personas concretas, con una inmensa amplitud de miras. El concilio Vaticano II formuló magistralmente esta actitud básica: "Los gozos y las esperanzas, las tristezas y las angustias de los hombres de nuestro tiempo, sobre todo de los pobres y de todos cuantos sufren, son a la vez los gozos y esperanzas, tristezas y angustias de los discípulos de Cristo" ${ }^{\prime 6}$.

La metáfora sugiere una última reflexión: Los nervios, en el ser humano, permiten la acción coordinada y con sentido. Pensar en el "nervio" humanista de la universidad sugiere también pensar en su dimensión organizativa que permitirá desplegar en la vida cotidiana el amor a lo humano, la sintonía con los problemas concretos y la integración de saberes. Mi reflexión irá más orientada a las características del humanismo pero las restantes aportaciones de la sesión aportarán sin duda esta dimensión organizativa sin la cual el contenido humanista de la vida universitaria desaparece arrastrado por el torbellino de los múltiples condicionamientos económicos, políticos, burocráticos y corporativos.

Lo que voy a decir es mi "sueño" universitario, mi utopía. Para resumir y sistematizar voy a expresarlo en diez proposiciones, como en un "decálogo".

"La etimología de todas estas palabras sugiere siempre una capacidad de "vibrar" y ser afectado por los sentimientos de los otros tanto en positivo como en negativo.

${ }^{6}$ Concilio Vaticano II. Constitución Gaudium et Spes n. 1 


\section{La universidad en la sociedad}

\section{I. Universidad de servicio}

Por lo que acabo de decir, podría parecer que sueño con una universidad elitista, una "torre de marfil", que reuniera a alumnos y profesores que tuvieran de entrada estas cualidades o que estuvieran especialmente dotados para ellas.

Al contrario, sueño en una universidad de servicio en la que las cualidades específicamente humanas antes mencionadas se pongan al servicio de toda la sociedad.

Seamos claros: no es esto lo que nos piden, al menos en primera instancia, nuestros alumnos, ni sus padres, ni siquiera los futuros empleadores de los alumnos. Piden en primer lugar competencias al servicio de sus intereses personales, y corporativos. Piden las competencias que les permitirán realizar una carrera profesional exitosa, o que permitirán aumentar los beneficios de las empresas. Estos intereses (a pesar de Adam Smith y del presidente de la General Motors) no coinciden siempre con el bien de toda la sociedad.

Para conseguir y mantener su "nervio humanista", la universidad debe sin duda formar profesionales con un alto nivel de competencias orientados a la práctica profesional. Pero jen qué consiste la profesionalidad? La ideología dominante entiende que un buen profesional es aquel que sabe aplicar los medios técnicos adecuados para conseguir los fines que le son propuestos en el marco organizativo y social vigente. Estos fines pueden estar marcados por intereses corporativos y económico que como hemos dicho no coincidan con el bien común. Un concepto más amplio de las profesiones sitúa a éstas proyectándolas sobre la sociedad de modo que la pregunta por el sentido social de los fines corporativos es intrínseca a una buena práctica profesional. Según esto no sería un "buen profesional" el que sabe crear productos bancarios de alto riesgo que proporcionan grandes beneficios a unos pocos y a la vez extienden el riesgo de un colapso global del sistema financiero.

La verdadera formación para la profesión incluye por tanto la reflexión sobre el "bien interno" de la profesión y sobre las virtudes necesarias en el profesional para poder aportar este bien interno ${ }^{7}$. De esta manera, el concepto humanista de profesión se proyecta sobre la persona (virtudes) y sobre la sociedad (bien interno). La profesión deja de ser sólo un medio al servicio exclusivo del propio provecho y se convierte también en un servicio a la sociedad.

${ }^{7}$ McINTYRE, A. (2007); HORTAL, A. (2002) 


\subsection{Una universidad "universalista", al servicio de todos}

Sueño con una universidad universalista, al servicio de todos. Con frecuencia se ha acusado a las universidades de ser un gran aparato cultural al servicio de la "reproducción" de las clases dominantes: las que acumulan poder político, riqueza económica y legitimidad cultural. Las universidades privadas caen especialmente bajo esta crítica porque su sistema de financiamiento las hace dependientes de las matrículas de los alumnos y de los fondos privados que provienen de clases ricas. El resultado es que tales universidades se convierten, de facto, en económicamente elitistas y discriminadoras.

Las universidades, si quieren ser fieles a su "nervio humanista" y ser universalistas no deberían resignarse a tal situación. Deberían luchar contra ella, aunque fuera para conseguir sólo pequeñas victorias, pequeños espacios de libertad al servicio de los más excluidos: becas personales, programas financiados, etc. Podríamos decir que deberían poner distancia entre el poder y su propia actividad.

En cambio, una universidad humanista debería acercarse a los pobres. Salir de los habituales barrios residenciales y establecerse cerca de barrios marginales. Enviar a sus alumnos a esos barrios. Sería la manera de visualizar una "opción por los pobres" sin la cual la universalidad del servicio es irreal: más bien el dinamismo espontáneo lleva a las universidades a hacer una tácita "opción por los grupos dominantes". Esto puede parecer un análisis simplista de la sociedad, basado en la idea de una contraposición radical de intereses entre grupos sociales. Sin necesidad de ello, sí se puede afirmar que con mucha frecuencia las preguntas acerca de los problemas que afectan a los más pobres quedan fuera del campo de visión de los programas universitarios y de las investigaciones con prestigio académico. La opción por los pobres implica una voluntad decidida de cercanía, de no excluir tales problemáticas de trabajo ordinario de la universidad.

Muchas Universidades latinoamericanas, conscientes de su ubicación social en sociedades muy desiguales, hicieron en los años 70 del siglo XX una "opción por los pobres": querían estar al servicio de la construcción de un país más justo y querían estar al servicio de los grupos sociales que sufrían la injusticia. En el mundo real en que vivimos, un mundo desigual e injusto, el humanismo universitario ha de ser un humanismo social. Este humanismo ha de ser el "nervio" de una universidad que se ponga al servicio a los pobres para cambiar las estructuras que crean pobreza, desigualdad y exclusión social. 
Eso no es fácil. Los poderes económicos, políticos y corporativos defienden sus intereses y tienen mucho poder para orientar las líneas estratégicos de una universidad. Recordemos las formas de ejercer el poder que analizaba Galbraith ${ }^{8}$. El más frecuente, en la actualidad, es la presión económica: las becas, las donaciones para programas de docencia e investigación pueden estar condicionadas a que la universidad no se signifique en su crítica a las estructuras injustas ni en su denuncia a los protagonistas de tales injusticias.

Los poderes económicos, políticos y culturales (o religiosos) ejercen también su poder mediante el uso de la fuerza o la amenaza de emplearla. Recordemos el asesinato de Ignacio Ellacuría y sus compañeros en El Salvador.

La situación sólo es tan extrema en determinados países y coyunturas históricas pero existen otras amenazas que también son muy eficaces: la divulgación de falsos rumores o escándalos o las campañas que cuestionan el rigor académico de sus trabajos, etc. Recordemos cómo los lobbies del petróleo han intentado descalificar a los científicos que planteaban el impacto de los combustibles fósiles sobre el medio ambiente.

Si quiere ser una "universidad para todos" y que el humanismo sea algo más que retórica comunicativa, la universidad (es decir, su profesorado y sus órganos rectores) ha de ser consciente de que sufrirá estas presiones y ha de prepararse para hacerles frente. Todo esto supone ganar libertad frente a todo tipo de poder.

Quisiera insistir en que una opción por los pobres no es una opción por un grupo particular. Es una opción para que la universalidad del servicio llegue a todos, incluidos los que habitualmente quedan excluidos. Supone sacar todas la consecuencias de este concepto fundamental de la modernidad que es la dignidad del ser humano: este valor propio de la persona humana que no depende ly no debería depender en la práctica) de las circunstancias particulares de nacimiento, cultura, etnia, género, nivel cultural, nivel económico, etc. Este valor universal de la persona expresado filosóficamente como dignidad, está claramente emparentado con los símbolos religiosos que en el cristianismo (y en otras tradiciones) realzan el valor de la persona humana al afirmar que el ser humano es "divino" porque es "hijo de Dios", que Dios se ha hecho "carne humana" y que se ha acercado especialmente a los pobres, los enfermos y los excluidos socialmente por ser "pecadores".

${ }^{8}$ GAlBRAITH, J.K. (1985) 


\subsection{Universidad al servicio del ser humano. El ser humano no es unidimensional}

Hemos hablado de humanismo como motor de una universidad al servicio universal... ¿̇de quién? Del ser humano, evidentemente. Pero ¿̇qué (o mejor quién) es el ser humano? Esta es la pregunta que según Kant pone en marcha todo la tarea filosófica. La pregunta es definitivamente importante para la universidad. Un concepto parcial y/o mutilado del ser humano llevará a una educación también parcial y deformada que reproducirá y aumentará los defectos y limitaciones del ser humano "víctima" de tal "educación".

Problema importante y a la vez difícil porque las diversas disciplinas rara vez se interrogan acerca de los presupuestos antropológicos sobre los que descansan. Por otra parte tales presupuestos no son socialmente inocuos: son correlativos a intereses sociales bien determinados y cambiar los presupuestos antropológicos implica en muchos casos enfrentarse a intereses sociales.

El P. Kolvenbach, que fue superior general de la Compañía de Jesús, decía que las universidades debían educar al "ser humano completo" y definíó cuatro dimensiones a las que la educación universitaria vinculada a los jesuitas debería atender: la profesionalidad (utilitas), la justicia (iustitia), el humanismo (humanitas) y la apertura libre a la trascendencia (fides) ${ }^{9}$. Al desarrollar estas dimensiones subrayaba que el peligro de las universidades era educar solamente la utilitas, una utilitas o profesionalidad limitada a la dimensión técnica, sin conciencia social, como apuntábamos en el apartado anterior.

La dimensión de iustitia alude a la dimensión social del ser humano que le lleva a reconocer derechos y deberes y a asumir compromisos. Esta dimensión queda frecuentemente ahogada por una concepción individualista del ser humano entendido como "homo oeconomicus". David Murillo resume así este concepto reduccionista del ser humano:

La percepción del individuo como homo oeconomicus, según la cual nuestra actuación en la sociedad viene determinada por unas supuestas características de nuestra conducta como son el materialismo, el individualismo, la racionalidad perfecta, el acceso-teórico- a toda la información disponible, la maximización de nuestras preferencias personales a través del mercado y la confusión general entre las variables de valor y precio de un bien ${ }^{10}$

\footnotetext{
${ }^{9}$ Kolvenbach, P.J. (2008)

${ }^{10}$ MuriLLO, David (2015), 204. David Murillo es profesor del Departamento de Ciencias Sociales de ESADE.
} 
La humanitas abre al ancho campo de la diversidad cultural, al respeto del otro, a las múltiples dimensiones de su propio desarrollo: el amor, la inteligencia, la creatividad.

La apertura a la trascendencia (fides) es un valor especialmente cuestionado en las sociedades occidentales fuertemente secularizadas. Sin embargo, asumiendo como es lógico su significación, vale la pena detenerse en su significación de "apertura". El ser humano no está encerrado en su deseo de sobrevivir aunque su dimensión biológica le oriente instintivamente en esta dirección. El ser humano es capaz, como decíamos al principio, de distancia respecto a su propio deseo, es capaz de libertad respecto a los objetos que necesita y por ello puede trabajar, transformar, innovar y crear. También puede amar, y extender su solidaridad incluso a seres humanos a los que no conoce y es también es capaz de gratuidad... Todo esto son "trascendencias" que definen lo más característico del ser humano. No son patrimonio sólo de los creyentes. La universidad humanista no puede ignorar estas dimensiones. No debe educar un homo oeconomicus cada vez más autocentrado (el Papa Francisco habla del peligro de la autoreferencia) "1 sino un ser humano completo al servicio de los demás. ${ }^{12}$

\subsection{LaUniversidad al servicio del "bien del ser humano". El problema del pluralismo}

Sueño con una Universidad al servicio del bien del ser humano. En los párrafos anteriores he precisado que se trata de todo el ser humano (la "persona completa" del P. Kolvenbach) y de todos los seres humanos (con una opción por los pobres que los incluya en el desarrollo humano). Pero actualmente lo que resulta problemático es la posibilidad de hablar de "el bien" del ser humano: de un bien único y definible.

Hoy en día somos más conscientes que en otras épocas de lo que significa la di-

\footnotetext{
${ }^{11}$ Exhortación Apostólica Evangelii Gaudium.

12 El Marco orientador del modelo pedagógico de ESADE explica la trascendencia como "espiritualidad" y la describe de esta manera: Al hablar de espiritualidad o dimensión espiritual, subrayamos interioridad y autoconocimiento; apertura al reconocimiento y al amor desinteresado de los demás que lleva al compromiso con los demás, especialmente con los más débiles y oprimidos. Espiritualidad implica también integración de las distintas dimensiones de la experiencia humana y planteamiento de las cuestiones últimas sobre el sentido de la vida. El cultivo adecuado de la dimensión espiritual desarrolla una manera de vivir en la que la libertad, la creatividad, la capacidad de amar gratuitamente, la solidaridad, el sentido de la justicia y la esperanza adquieren un lugar central. http:// www.esade.edu/web/esp/about-esade/aboutus/mission-values/pedagogical-model. Última visita 28 septiembre 2015.
} 
versidad cultural. Las culturas son realmente proyectos diferenciados de desarrollo del ser humano y optan por modelos de sociedad muy distintos. También optan por valores muy diferentes como base de su desarrollo personal y social.

En estas condiciones, ¿̇podemos seguir hablando, como hacía Aristóteles, de un ideal de "vida buena"? ¿ ¿Hay un solo modelo de "vida buena? Incluso en el interior de una misma cultura existen profundas diferencias ideológicas sobre aspectos fundamentales de la vida personal y social: el género, el consumo, la relación con la naturaleza se construyen de manera muy diferente en el interior de una misma cultura.

Creo que para clarificar el debate conviene distinguir diferentes preguntas a las que intentaré responder en este apartado y en el siguiente:

La primera cuestión es por decirlo así "ontológica": ¡̇Eiste un bien o más bien deberíamos abrazar un "politeísmo de valores ${ }^{13}$ y admitir que el ser humano puede realizarse plenamente en una pluralidad de opciones por valores fundamentales? En el segundo caso, ìse puede admitir que algunos proyectos de humanidad son más válidos que otros?

La segunda pregunta es de índole más "epistemológica": ¿Podemos llegar al conocimiento de este "bien del ser humano" en el caso de que exista? ¿ Cabe la posibilidad de un "discernimiento" que permita distinguir proyectos de realización humana más válidos que otros?

Finalmente, una cuestión de convivencia, diálogo y posible progreso: ¿̨Se puede imponer una determinada concepción del bien del ser humano? ¿En qué condiciones y circunstancias? ¿Cabe la posibilidad de un diálogo enriquecedor entre opciones diferentes?

Estas preguntas pueden parecer abstractas y poco aplicables pero son fundamentales para establecer las bases de una convivencia verdaderamente enriquecedora en los campus de nuestras universidades. La internacionalización de las universidades es un proceso imparable y ninguna universidad puede ya pensar en tener un alumnado y un profesorado culturalmente homogéneo. Como dice Adela Cortina, esta situación puede gestionarse como una mera "coexistencia" preocupada por

${ }^{13}$ Cortina, A. (1998) 
evitar conflictos o bien puede asumirse como un desafío que ofrece la posibilidad de una "convivencia" mutuamente enriquecedora no sólo a nivel personal sino como proyecto cultural de la misma universidad.

Esta cuestión tiene un alcance que va más allá de la convivencia entre personas muy diferentes en un mismo campus. La cuestión es si la misma actividad docente y de investigación queda marcada de manera enriquecedora, por la diversidad de perspectivas. ¿̇Podemos pensar, por ejemplo, en proyectos de medicina que incorporen seriamente las antropologías nacidas en las grandes culturas orientales? ¿Podemos pensar que en el futuro nuestra medicina "occidental" evolucionará bajo el influjo de estas otras antropologías? Podemos pensar que la gestión de las personas puede beneficiarse de semejante diálogo intercultural? ¿̇Puede pensarse lo mismo de las finanzas? Generalizando más, la "técnica" tal como la conocemos, $\dot{\partial}^{\text {no }}$ es el resultado de un proyecto cultual muy determinado, del cual empezamos a experimentar las fisuras? ¿2Podremos llegar a construir una técnica sobre premisas valorativas más integradoras de la diversidad de proyectos culturales?

En esta situación, sueño con una universidad que viviera la distinción entre éticas de mínimos y éticas de máximos que propone A. Cortina y que lo hiciera de modo dinámico y en proceso.

La ética de mínimos busca y establece los "mínimos de justicia" de la convivencia humana. Marca las líneas rojas que no deben transgredirse si se quieren respetar los grandes valores que precisamente hacen posible la convivencia: la dignidad de la persona, la libertad, la justicia, la solidaridad. Se expresa en los derechos humanos reconocidos como base ética del ordenamiento jurídico en las democracias representativas actuales. Es una ética que aunque se dice "de mínimos", no es en modo alguno "minimalista" porque los mínimos son muy altos: el respeto a los derechos humanos.

Sueño con una universidad en la que los mínimos de convivencia se reelaboren continuamente: en la que, lo que en un momento dado parecía "normal", se descubra luego que es "intolerable". Esto ha sucedido ya en algunos campos: por ejemplo, el del fumar. Lo que hace unos años se veía "normal", como fumar en las aulas, ahora se ha convertido en un atentado a la salud de los otros y de uno mismo y entra dentro de lo prohibido.

Pero también son necesarias éticas de "máximos" que busquen la felicidad y la autorrealización de las personas. La ética, decía Aristóteles, no se preocupa sólo de aclarar lo que es conveniente para una "vida buena", debe también capacitar para 
poder vivir esta vida buena. Dicho de otra manera, además de saber lo que hay que hacer hay que querer hacerlo (amar el bien) y hay que ser capaz de hacerlo (adquirir la fortaleza necesaria): es una cuestión de conocimiento y de "virtudes" en su sentido etimológico de "virtualidades", de posibilidades.

Las éticas de máximos ofrecen distintos caminos para alcanzar la felicidad de la persona, una felicidad adecuada a su verdadero ser o a la opción de vida que ha realizado. Las éticas de máximos ofrecen también los caminos de búsqueda necesarios en esta tarea: tradiciones con solera, métodos de iniciación y progreso, y entorno comunitario, en muy diferentes formas.

Sueño también con universidades donde diferentes éticas de máximos convivan respetuosamente y en diálogo e intercambio. Que la multiculturalidad no desemboque en "achatamiento" de las posibilidades humanas ni en aceptación acrítica de una ética hedonista basada en el consumo ilimitado, sino una oportunidad de descubrir nuevas posibilidades humanas, explorarlas, corregirlas y enriquecerlas.

\subsection{Las universidades frente al relativismo cultural}

Al comienzo del apartado anterior planteaba los interrogantes abiertos por la situación de pluralismo cultural: $\dot{\imath}$ Existe un "bien propio del ser humano"? ¿Este bien, ¿Puede ser conocido? La respuesta de Adela Cortina se orienta a mostrar las consecuencias sociales del relativismo absoluto (sea ontológico o epistemológico): si nada es verdadero, todo es igualmente válido y en definitiva, no se puede argumentar contra la "ley del más fuerte". El más fuerte impone su ley y el oprimido ni siquiera tiene el recurso de decir: "yo tengo la razón de mi parte, eres injusto".

Pienso que esta afirmación es básicamente cierta: no todo es igual ni vale lo mismo. Y por lo tanto unos valores son mejores que otros para el ser humano.

También pienso que nadie puede afirmar que conoce de una vez por todas los "valores auténticamente humanos" o el "bien del ser humano", o al menos que nadie puede afirmar que su manera de aplicar los valores más generales a una situación concreta no admite discusión. Pero, a la vez, creo que el diálogo entre posiciones diversas puede llegar a consensos enriquecedores no sólo de orden fáctico sino también de orden racional. Por lo tanto, el diálogo es necesario y es útil. Y las posiciones fundamentalistas que se niegan al diálogo quedan descalificadas para la convivencia humana. 
Esta última es una afirmación con consecuencias. Como veremos más adelante, cuando el diálogo intercultural llega a ser diálogo interreligioso, se constata que las religiones difícilmente están dispuestas a "aprender" unas de otras. Y un diálogo en el que no se puede aprender nada no es tal diálogo, sino a lo más una conversación cortés.

Por lo tanto, pienso que cada uno puede defender sus ideas y pretender llevarlas a la práctica con dos condiciones: la disposición al diálogo y al mutuo aprendizaje por un lado, y por otro el respeto a las "líneas rojas" de la ética de mínimos en el nivel en que estén formuladas.

Insisto en que debe haber búsqueda y debate para que haya humanismo. No vale reducir las aspiraciones del humanismo a unos mínimos consensuados de una vez para siempre que eliminen de la Universidad el cuestionamiento del humanismo vigente (tal vez todavía elitista, machista, clasista, etnocéntrico). El humanismo en un mundo plural ha de ser esencialmente dialogante y buscador de paz en justicia y libertad. Y por lo dicho antes, ha de ser humilde. No estoy muy seguro de que la universidad "realmente existente" entre a fondo en esta cuestión. Y sin embargo, la creciente internacionalización de nuestros centros lo exige cada vez con mayor urgencia.

Pienso que el pluralismo cultural plantea a las universidades un reto muy intrínseco: orientadas a la búsqueda del saber y de la verdad, las universidades no pueden marginar esta cuestión ni enfrentarla a un nivel meramente pragmático. Es su responsabilidad convertir el desafío en oportunidad para alcanzar cotas de convivencia más humana no sólo en su propio campus, sino en la sociedad global en la se insertan.

Por lo tanto sueño con universidades que asumen el reto de la multiculturalidad y por ello rechazan los fundamentalismos, propician el diálogo, proponen nuevos valores y de esta manera colaboran a la construcción de sociedades más interculturales.

\subsection{Recuperar el potencial humanizador de las religiones}

Quisiera empezar con una anécdota personal. Hace ya bastantes años, el que luego sería superior general de los jesuitas, el padre Adolfo Nicolás, reflexionaba sobre el diálogo religioso ante un grupo de jesuitas que participarían en la Congregación 
general 34. Su mensaje ${ }^{14}$ venía a decir: "El diálogo entre religiones es necesario y tiene que partir de los hechos, de la realidad. La realidad es que las grandes tradiciones religiosas de Oriente (el hinduismo, el budismo, su variante zen, etc.) producen frutos innegables de santidad, sanación, paz, justicia, amor... Esto no es discutible porque es un hecho. El cristianismo ha de reconocer la presencia de Dios en estas tradiciones. Esto plantea serios problemas teológicos al cristianismo, pero hay que afrontar estos retos. En el diálogo interreligioso se debe entrar con buena formación, con una identidad sólida, precisamente para poder aportar algo en bien de la humanidad."

De esta reflexión retengo la afirmación de que las grandes tradiciones religiosas (incluido, claro está el cristianismo en sus diferentes formas) pueden hacer grandes aportaciones a la vida humana, precisamente en la línea de lo que los cristianos llamamos el "Reinado de Dios", el Proyecto de Dios sobre la humanidad, el proyecto de que el ser humano construya un mundo humano y alcance la plenitud y la felicidad en comunión con Dios mismo.

También es cierto que las noticias diarias transmiten otra realidad: la de unas religiones que llevan a la división y al enfrentamiento, a veces sangriento, entre grupos humanos.

Por otra parte, el fenómeno de la secularización, tan fuerte en Occidente y especialmente en el mundo académico, relega el hecho religioso al ámbito de la conciencia individual lo cual bloquea la posibilidad de un diálogo en profundidad entre las diversas religiones y la sociedad secularizada, un diálogo que desbloqueara la rigidez de uno y otro lado y abriera camino a la aportación positiva que pueden tener las religiones al desarrollo humano.

La Universidad debería ser un lugar privilegiado para este diálogo. En efecto, el diálogo intercultural que reclamaba en el apartado anterior queda bloqueado si no se llega al diálogo interreligioso: de hecho las religiones han configurado el núcleo fundamental de los valores y la concepción del mundo de cada cultura. Sin llegar a la religión el diálogo intercultural se queda corto.

Por otra parte, tanto el fenómeno de la internacionalización como el nivel académico de la convivencia reclaman este tipo de diálogo. También hay que reconocer

\footnotetext{
${ }^{14}$ Guardo unas notas puramente privadas de aquella reunión. Lo que digo aquí, creo que refleja bien el mensaje de Adolfo Nicolás, pero cualquier error de interpretación es responsabilidad exclusivamente mía.
} 
lo contrario: el mundo universitario es el ámbito más secularizado de la sociedad tanto en Occidente como en el resto del mundo y esto hace más difícil el diálogo... aunque también más necesario.

¿Cuáles son las dificultades principales de este diálogo? Por el lado "secular" se reclama una "ética de mínimos" basada en la reducción del fenómeno religioso al ámbito de la opción puramente individual: la religión puede existir en el campus universitario pero sólo en el interior de la conciencia individual, sin manifestación comunitaria ni relevancia en la convivencia. Sin duda existen razones para esta posición: experiencias históricas, algunas dolorosas, que han llevado a esta situación de mínimos. Pero para cualquier estudioso de la religión desde una perspectiva científica (sociológica o antropológica, no confesional ni dogmática) es evidente que las religiones necesitan un espacio social comunitario y reclaman cierta intervención de la vida social.

Por el otro lado, las religiones y, en el caso español, el catolicismo, en su relación con la modernidad y la secularización, reclama espacios públicos y relevancia social pero con frecuencia lo hace desde posiciones cultural y políticamente premodernas que son interpretadas, con razón, como una voluntad de recuperar poder político.

En la experiencia concreta de profesores, alumnos y PAS, creo que esta situación es vivida en forma de desinterés, desconcierto y a veces miedo. Para las personas que han hecho una opción decidida por el agnosticismo o el ateísmo, el diálogo ha dejado de ser interesante. Por otra parte, muchos creyentes se ven incapaces de hablar públicamente de estos temas por falta de formación, por intuir un ambiente de indiferencia o claramente hostil, o porque también ellos tienen otras cosas que les preocupan más en la práctica...

Sin embargo, pienso que las universidades pueden hacer mucho para desbloquear estas situaciones y que ello forma parte de su misión al servicio de la Sabiduría. Creo que deberían distinguirse dos campos: el más propiamente institucional y la distinción entre religión y procesos espirituales, que trataré en el siguiente apartado.

Desde un punto de vista institucional, la universidad podría ayudar a reflexionar más a fondo sobre las religiones. La sociedad occidental trata estos problemas partiendo de un dualismo básico que divide la sociedad en "creyentes" y "no creyentes". Pero esta es una dicotomía heredada del racionalismo y de la ilustración que ya no corresponde a la realidad. En las complejas sociedades actuales deberíamos ver que cada campo es internamente plural: hay ateos militantes, agnósticos indiferentes, agnósticos que sienten la gravedad del mal en el mundo y 
que no pueden admitir un dios que "permite todo esto"... En el campo "creyente" hay personas "premodernas", "modernas" y "postmodernas". Hay creyentes de otras religiones: musulmanes, sikhs... Hay múltiples formas de religiosidad que simplificando podríamos situar en el ámbito de "la Nueva Era". ¿Dónde está la frontera exacta de cada grupo? Muchos hablan de una "religión a la carta" en la que cada uno construye su propia religión en base a la "oferta" existente ${ }^{15}$.

En esta situación parece (socialmente hablando) tanto o más importante "cómo" se cree (o no), que "lo que" se cree. Lo importante es si existe capacidad de diálogo o si se es fundamentalista o integrista. Lo importante es si la fe religiosa (y también la no fe) es fuente de paz y solidaridad o de violencia y exclusión. Lo importante es si las diferentes fuentes de sentido quieren colaborar en la construcción de un mundo más justo, libre y pacífico. Y como el mundo actual es muy injusto (como lo era el de Jesús), esto implica comprometerse en la lucha por la justicia y no sólo por la caridad. Aunque pueda parecer reductor, creo que el criterio de la colaboración de cada religión a una sociedad "humana" (o en busca de "humanización") debería ser el "criterio de verdad" decisivo, al menos de modo negativo: si no contribuye, de hecho, no es "buena religión" ni religión "verdadera".

Dicho de otro modo, una consideración humanista de las religiones debería preocuparse más de dialogar sobre los distintos modelos de santidad y su repercusión social que sobre la doctrina: ¿̇ qué tipo de persona conduce un determinado modelo religioso? ¿Qué aporta a la sociedad? (o qué no aporta) ${ }^{16}$. Me parece que, en el mundo plural en el que nos movemos, el acento se debe desplazar de las cuestiones dogmáticas (con pretensión ontológica: lo que es "verdad") a la verdad que se hace en el amor y al amor que se realiza en la (búsqueda de la) verdad para tomar dos enfoques que remiten al apóstol Pablo y a Benedicto XVI. ${ }^{17}$

Todo esto tiene una repercusión institucional universitaria. Los modelos actualmente existentes de universidad asumieron humanismos laicos y humanismos religiosos, contraponiéndolos entre si. La institucionalización de estos dilemas ha dado lugar a universidades laicas y a universidades "confesionales". Pero tal vez el problema es si deberíamos pasar a universidades conscientes de su pluralismo y que en lugar de ocultarlo y basar la convivencia pacífica en su interior en el silencio sobre el

\footnotetext{
${ }^{15}$ DAVIE, G. (2010)

${ }^{16}$ Melloni, X. (2003), especialmente el capítulo 9.

${ }^{17}$ El paréntesis intercalado es mio. El título de Caritas in Veritate invierte la frase de Pablo en Efesios, 4, 15.
} 
tema, hicieran explícito el pluralismo, y lo convirtieran en materia de un diálogo implicado en los grandes problemas de la humanidad. Se trataría de un pluralismo "confesante" que reconoce el hecho del pluralismo y "lo hace funcionar" para que despliegue la riqueza humana que contiene.

En resumen sueño con una universidad que asume la cuestión religiosa, invita a las religiones a resituarse y ser autocríticas en el mundo plural, globalizado y multirreligioso en el que vivimos, invita al pensamiento secular a resituar el tema religioso y rescata el poder humanizador de las religiones cuando son fieles al impulso humanizador de sus orígenes.

\subsection{Cultivar la interioridad, abrirse a la "espiritualidad", trascender en todas direcciones}

En el apartado anterior soñaba con una universidad que fuera capaz de desbloquear el potencial humanizador de las religiones de manera adecuada a un mundo secularizado y plural. Pero no nos engañemos: en la universidades occidentales un amplio porcentaje de universitarios (¿una mayoría?) no "están a tiro" de la influencia de las religiones en su dimensión institucional.

Estudiantes y profesores son en su mayoría "individuos sin iglesia". Han sido educados en ambientes decididamente laicos y no han tenido ocasión de captar la hondura humana de los grandes maestros religiosos ${ }^{18}$. No pertenecen tampoco a otro tipo de "comunidades" con sentido de pertenencia y en el que pudieran cultivar su propio humanismo. Su proceso de socialización ha sido un proceso de individualización ${ }^{19}$ y se ven abocados a vivir su propia vida como un itinerario personal: en cierto modo son llevados a construir su vida como se podría construir una obra de arte única. El drama, como subraya Bauman ${ }^{20}$ es que la misma sociedad que les plantea ineludiblemente las grandes opciones de la vida, no les proporciona los medios de trabajo interior que les capacitaría para ello.

La sociedad postmoderna y consumista ofrece en cambio caminos ya marcados de "realización": el éxito profesional que da acceso a las típicas vías de desigualdad

\footnotetext{
${ }^{18}$ Armstrong, K. (2007).

19 Beck, U. y Beck-Gernsheim, E. (2003).

20 BAUMAN, Z. (2009).
} 
social: el poder, el prestigio del status y el dinero que en nuestra sociedad es el bien dominante, el que da acceso a todos los otros bienes ${ }^{21}$.

Sin embargo, no todos aceptan acríticamente esos caminos: los voluntariados son aceptados; las prácticas solidarias y los stages en países del sur tienen gran aceptación y para muchos tales experiencias son auténticos caminos de iniciación que les abren a perspectivas humanas y trascendentes antes apenas entrevistas.

Este tipo de experiencias prácticas necesitan de "herramientas" para educar la propia interioridad. La interioridad, cuando se cultiva adecuadamente, se abre fácilmente a experiencias diversas que agrupamos bajo la palabra "paraguas" de "espiritualidad".

Por otra parte, la filosofía y la antropología están enfocando su mirada hacia lo que algunos llaman la dimensión "espiritual" del ser humano, entendida no como perteneciente a la esfera religiosa sino como algo constitutivo de la experiencia humana, susceptible de educación y desarrollo en ámbitos y lenguajes religiosos pero también "laicos"22. Las experiencias que se pueden calificar de místicas abundan y sería injusto decir que todas ellas están simplemente en los límites de la autoayuda: algunas son experiencias serias ${ }^{23}$.

Coherentemente con este planteamiento teórico, se constata que determinadas prácticas que son vividas como "libres de adscripción religiosa" como yoga, mindfulness, meditación (en el sentido oriental de la palabra) encuentran amplia acogida.

Todo ello confluye en un nuevo planteamiento de la educación en la universidad. La universidad debería ofrecer a todos sus miembros medios para desarrollar su "interioridad", una interioridad abierta a diversas formas de experiencia "espiritual". Esta formación no debería ser sólo posible en un ámbito religioso sino que debería ser abierta a toda persona sin adscripción religiosa.

No es fácil. Por el lado "laico" subsiste mucho recelo respecto a todo lo que puede parecer intento "eclesiástico" de recuperar influencia. Y con frecuencia el tema no interesa lo suficiente como para adoptar la actitud de indagación que exige.

\footnotetext{
${ }^{21}$ Walzer, M. (1983).

${ }^{22}$ Compte-Sponville, A. (2006).

${ }^{23}$ Nos referimos a autores como Eckhart Tolle, Toni Parsons, Jean Klein, David Carse, etc.
} 
Por el lado "creyente" (católico) esta nueva apertura resulta todavía muy lejana a la concepción tradicional de la Iglesia. Aunque ya pocos crean que "fuera de la Iglesia no hay salvación", pocos sacan todas las consecuencias de afirmar que "el Reino es más amplio que la Iglesia" y de que el Espíritu de Dios "llena el universo" como dice un canto frecuente en las eucaristías de nuestras parroquias.

Por otra parte, es evidente que esta indagación tiene sus peligros: por ejemplo, no "buscar el Espíritu" sino buscar una paz y serenidad de un nivel mucho más superficial. "Tecnificar" los procesos de aprendizaje espiritual en sintonía con la mentalidad eficacista e instrumental de nuestra sociedad. Sobre todo, el peligro de llegar pronto a una "tranquilidad" que en lugar de liberar para el amor, la solidaridad y el compromiso, adormezca en un bienestar egocéntrico... El mensaje de Jesús que anunciaba la Buena Noticia a los pobres quedaría así gravemente mutilado.

Y sin embargo, hay que intentarlo. Los cambios profundos en la espiritualidad han tenido y tendrán sus riesgos. S. Ignacio y Santa Teresa fueron repetidamente acusados de "alumbrados" y sufrieron por ello. Pero su experiencia espiritual y su magisterio abrieron caminos inmensos a las generaciones siguientes de cristianos. Pienso que nuestra generación está llamada a realizar una segunda revolución espiritual que aprenda de todas las grandes religiones y que se ofrezca a todos los pueblos y personas. Esta revolución no sólo mejoraría la calidad humana de las personas sino que, paradójicamente, haría a la universidad más "eficiente" en la producción de conocimiento y saber. Al desarrollar su libertad interior y su apertura a la realidad haría a estudiantes y académicos más capaces de innovación y creatividad en un momento en que los problemas de la humanidad piden soluciones imaginativas, realmente "disruptivas".

\section{La difícil puesta en práctica}

Como decía al principio, he intentado formular el "sueño" de una universidad humanista... y tal vez el cuadro sea excesivamente exigente. El papel lo aguanta todo, pero la realidad es difícil de manejar. Por ello quiero dedicar los dos últimos números de este "decálogo" a reflexionar sobre dos cuestiones. En primer lugar, sobre el tipo de proceso docente que podría involucrar al alumno para que participe activamente en su propia formación. En segundo lugar sobre la comunidad universitaria y su conciencia de misión. 


\section{I. El proceso docente.}

El P. Kolvenbach en sus reflexiones sobre las universidades vinculadas a la Compañía de Jesús, decía que el proceso educativo debía orientarse a formar futuros profesionales que fueran compasivos, conscientes, competentes y comprometidos. Pienso que estas cuatro cualidades tienen una lógica interna de modo que cuando una se realiza en cierta medida, empieza a reclamar la siguiente. El conjunto dibuja, como decíamos, un proceso de involucración del alumno que llegará a ser un profesional.

- No está de moda decir que un futuro profesional ha de ser compasivo. Muchos piensan más bien que para triunfar hay que ser "duro" y que el aprendizaje universitario debe formar personas "duras". Sin embargo, el buen profesional debe captar, entender y aceptar la realidad del mundo y de las personas que le rodean. Cuanto más capaz sea de "meterse en su piel" más entenderá los problemas "desde dentro" y más capaz será enfrentarlos en su realidad. La persona "dura" no acepta la realidad como es y sin aceptación no hay comprensión ni solución auténtica. En la formación clásica, las humanidades desempeñaban un papel muy importante entre otras cosas porque a través de ellas (la literatura, incluido el teatro, la historia, etc.) el estudiante se hacía capaz de comprender y vibrar con los sentimientos y situaciones más diversas, aunque fueran muy distantes de su experiencia habitual ${ }^{24}$. La compasión es, como decía al principio, citando el comienzo de la Gaudium et Spes, la capacidad de hacer propias las emociones, las alegrías, los sufrimientos y las esperanzas de los demás.

- La compasión desemboca en consciencia porque la compasión, o es abierta y profunda o no es compasión sino sensiblería. La verdadera compasión implica interés por el otro y por lo otro y el interés lleva a conocer más amplia y profundamente. El P. Kolvenbach decía que los estudiantes, a lo largo de su formación

dejen entrar en sus vidas la realidad perturbadora de este mundo, de tal manera que aprendan a sentirlo, a pensarlo críticamente, a responder a sus sufrimientos y a comprometerse con él de forma constructiva, con el fin de que aprendan a percibir, pensar, juzgar, elegir y actuar a favor de los derechos de los demás, especialmente de los más desaventajados. ${ }^{25}$

\footnotetext{
${ }^{24}$ Ver Nussbaum, M. C. (2010), especialmente Cap. 6.

${ }^{25}$ KolvenBACH, P. H., "El servicio de la fe y la promoción de la justicia en la educación universitaria de la Compañía de Jesús en Estados Unidos", Universidad de Santa Clara-California, octubre de 2000, n 42. Ver KolvenbaCH, P. H. (2008).
} 
La universidad humanista debería ofrecer a sus estudiantes la posibilidad de este tipo de experiencia "perturbadora" que no sólo amplia el conocimiento sino que pone a la persona en situación de cuestionar sus presupuestos sociales y culturales, flexibilizando su captación de la realidad.

No se trata sólo de ampliar la consciencia de lo real sino también de profundizarla. El conocimiento universitario se construye a base de modelos y teorías que permiten enfrentar problemas y solucionarlos. Los modelos y teorías implican siempre una cierta simplificación ("modelización") de lo real. El peligro es que tales modelos y teorías funcionen en la práctica como "pantallas" interpuestas entre el estudiante y la realidad, de tal manera que esta pierda sus rasgos humanos. El estudiante puede aprender a manejar fórmulas y modelos desentendiéndose de la realidad humana que encierran.

Por esto, una docencia "profunda" 26 debe llevar al estudiante, a través de la teoría hasta la realidad histórica y social de los problemas planteados. La teoría debería contextualizarse siempre de manera histórica y sociológica y también psicológica para que las personas no desaparecieran tras los números y los símbolos matemáticos.

- La compasión y la consciencia reclaman la respuesta madura de una gran competencia. El refrán dice que "el infierno está empedrado de buenas intenciones" y, de modo semejante, la historia de los países y de las empresas está llena de ensayos y pruebas que no dan resultado, no por mala fe de sus protagonistas sino a causa de su incompetencia profesional. Precedida de la compasión y la consciencia, la competencia se sitúa en un "relato" que le da sentido: no se estudia simplemente para, en el futuro, ganarse la vida sino para poder enfrentarse a problemas reales y solucionarlos en beneficio de los implicados (los stakeholder).

- Finalmente, los profesionales competentes serán llevados a un compromiso con su trabajo que ya no será visto ni vivido como un instrumento al servicio exclusivo del éxito económico y del status social, sino como un servicio a la sociedad y en concreto a sus grupos más excluidos. De este modo, la profesionalidad se entiende de modo transformador: no se trata de acomodarse a la realidad tal como es sino de transformarla en beneficio del ser humano. Por otra parte, el

${ }^{26}$ Como ha pedido repetidamente el actual Superior General de la Compañía de Jesús, A. Nicolás a las Universidades vinculades a la Compañía de Jesús. Depth, Universality, and Learned Ministry: Challenges to jesuit higher Education today. Méjico, 2010. 
compromiso lleva a nuevas experiencias, que ofrecen un nuevo campo a la compasión, reiniciando el ciclo del aprendizaje continuo.

Creo que una parte significativa del alumnado es capaz de involucrarse una proceso transformador a la vez de si mismos y de la realidad y que uno de los grandes retos de una universidad con "nervio" humanista es precisamente concebir su modelo pedagógico como un proceso en el que la maduración personal y la capacidad de transformación de la realidad crezcan a la par.

\section{2. "Para educar un niño hace falta toda la tribu"27}

José Antonio Marina ha popularizado este refrán africano que recuerda que la formación de un niño, pero también de un joven o un adulto no es obra exclusiva de los padres o los maestros (las personas en las que se delega tal tarea) sino también de todo el contexto organizativo, social y cultural en el que el proceso educativo se desarrolla: en la universidad, todos somos educadores: dirección, servicios académicos, mantenimiento, profesores...

No sólo somos educadores todas las personas sino el mismo funcionamiento universitario, el funcionamiento de la organización como tal. Porque los estudiantes captan "por ósmosis" los valores que realmente impregnan la organización. Por ello es importante vigilar y trabajar la "cultura organizativa": los valores, intereses, pautas de conducta que realmente funcionan y que pueden estar alejadas de las proclamaciones verbales de la Misión, la Visión y los Valores proclamados. La coherencia entre valores proclamados y los valores vividos es esencial y la incoherencia es destructora.

No podemos entrar en el detalle de la problemática organizativa y de liderazgo capaz de "encarnar" el "nervio humanista" de la universidad. Sólo quisiera subrayar la necesidad de que el horizonte de sentido esté constantemente presente en el día a día del funcionamiento ordinario y "prosaico" de la universidad.

El Papa Francisco ha señalado la necesidad de que lo pequeño y cotidiano y el horizonte de sentido estén siempre iluminándose recíprocamente. Termino estas reflexiones sobre el nervio humanista de la universidad con sus estimulantes palabras:

Me ha impresionado siempre una máxima con la que suele describirse la visión de lgnacio: Non coerceri maximo, sed contineri minimo divinum est. He reflexionado largamente sobre esta frase por lo que toca al gobierno, a ser superior: no tener límite para lo grande,

${ }^{27}$ http://www.joseantoniomarina.net/libro/aprender-a-vivir/ (consultado el 28 de septiembre de 2015). 
pero concentrarse en lo pequeño. Esta virtud de lo grande y lo pequeño se llama magnanimidad, y, a cada uno desde la posición que ocupa, hace que pongamos siempre la vista en el horizonte. Es hacer las cosas pequeñas de cada día con el corazón grande y abierto a Dios y a los otros. Es dar su valor a las cosas pequeñas en el marco de los grandes horizontes, los del Reino de Dios".

\section{Bibliografía}

ARMSTRONG, K. (2007) La gran transformación, Barcelona, Paidós,

BAUMAN, Z. (2009) El arte de la vida. De la vida como obra de arte, Barcelona, Paidós.

BECK, U. y BECK-GERNSHEIM, E. (2003) La individualización: el individualismo institucionalizado y sus consecuencias sociales y políticas, Barcelona, Paidós

Compte-Sponvilue, A. (2006) El alma del ateísmo, Barcelona, Paidós

CORBí, M. (2007) Hacia una espiritualidad laica. Barcelona, Herder

CortinA, A. (1998) Los ciudadanos como protagonistas, Barcelona, Galaxia Gutenberg / Círculo de Lectores

DAVIE, G. (2010) Sociología de la religión, Madrid, Akal

GalbRAITH, J. K. (1985) La anatomía del poder, Barcelona, Plaza Janés

HORTAL, A. (2002) Ética general de las profesiones, Bilbao, Descleé de Brouwer

KolvenBaCH, P. H. (2008) Discursos universitarios, Madrid, UNIJES

MclNTYRE, A. (2007) Tras la virtud, Barcelona, Crítica

MelloNI, J. (2003) El uno en lo múltiple, Santander, Sal Terrae

MuriLLO, D. (2015) De Walmart a Al Qaeda. Una lectura interdisciplinar de la globalización, Barcelona, Libros de cabecera

NicolAs, A. (2010) "Depth, Universality, and Learned Ministry: Challenges to jesuit higher Education today", México 
Nussbaum, M.C.(2010) Sin fines de lucro, Madrid, Katz

Walzer, M.(1983) Las esferas de justicia, México, FCE

\section{Páginas web citadas}

http://www.joseantoniomarina.net/libro/aprender-a-vivir/ Consultado el 28 de septiembre de 2015.

http://www.esade.edu/web/esp/about-esade/aboutus/mission-values/ pedagogical-model

Última visita 28 de septiembre de 2015. 